\title{
Da medicina tradicional chinesa à prática de acupuntura médica baseada em evidência
}

\author{
From traditional chinese medicine to the practice \\ of acupuncture based in evidence
}

\author{
Chin An Lin
}

Lin CA. Da medicina tradicional chinesa à prática de acupuntura médica baseada em evidência / From traditional chinese medicine to the practice of acupuncture based in evidence. Rev Med (São Paulo). 2013 jul.-set.,92(3):213-5.

\begin{abstract}
RESUMO: Acupuntura é uma prática milenar que faz parte da chamada medicina tradicional chinesa. Tem sido praticada por milhares de anos na China e alguns países do continente asiático. Como tem sido descrita como efetiva no tratamento de diversas doenças e condições, a acupuntura tem sido considerada um instrumento útil na prática da saúde. Da prática primitiva até os dias de hoje, a acupuntura tem ganhado novos adeptos, atraindo assim a atenção da comunidade científica, a fim de entender melhor o seu mecanismo de ação e sua efetividade. Vários estudos têm sido feitos e publicado envolvendo acupuntura, mas há ainda controvérsia acerca de sua eficácia e efetividade. Novos estudos devem ser feitos para estabelecer o real papel da acupuntura no tratamento de diversas doenças e condições.
\end{abstract}

DESCRITORES: Acupuntura; Medicina tradicional chinesa; Doenças.

\begin{abstract}
Acupuncture is a healing technique practiced for thousand years in China and some Asian countries, and was considered as part of Traditional Chinese medicine. As it claimed to be effective in treatment of several diseases and conditions, it has been described as useful instrument in ancient practice. From primitive to nowadays practice, acupuncture is gaining more adepts, thus attracting attention of scientific community in order to better understand its mechanism and its effectiveness. Several studies have been published concerning to acupuncture, but there is still controversy about its efficacy and effectiveness. Further studies should continue to be performed in order to establish the real role of acupuncture in treatment of several diseases and conditions.
\end{abstract}

KEYWORDS: Acupuncture; Medicine, chinese traditional; Disease.

Departamento de Clínica Médica, Faculdade de Medicina da USP, Disciplina de Clínica Geral e Propedêutica, Hospital das Clínicas da FMUSP, Centro de Acupuntura, Instituto de Ortopedia e Traumatologia, HCFMUSP. Pesquisador do Laboratório de Poluição Atmosférica Experimental da FMUSP.

Endereço para correspondência: Chin An Lin. Av. Dr. Enéas Carvalho de Aguiar, 255, Prédio dos Ambulatórios, $4^{\circ}$ Andar, Sala 6. Cerqueira César, São Paulo, SP. CEP 05403-000. e-mail: chin.lin@hc.fm.usp.br 
A história da Civilização Humana remete a um início nada glamoroso. A luta pela sobrevivência da espécie impeliu a um avanço e desenvolvimento de práticas como agricultura, domesticação de animais, construção e melhorias de moradias, desenvolvimentos de vestuário e medicina. Medicina, um dos pilares da ciência aplicada na prática, teve um começo nada auspicioso. Envolvida em crenças e conceitos não científicos que eram mais práticas de superstição e feitiçaria ou pajelança, por muito tempo a medicina esteve ligada e a cargo de feiticeiros. Na China antiga, não havia exceção, o médico era identificado como alguém que praticava adivinhações e sabia dos meios de expulsar os maus espíritos ou conhecia meios de agradar aos deuses para melhorar a saúde dos seus pacientes. $\mathrm{Na}$ evolução dos caracteres de ideogramas chineses, o desenvolvimento dos ideogramas ao longo da história mostra a diferença da posição social e da profissão do médico. No início, o ideograma que significa médico começa com a palavra feitiço 巫, após alguns séculos de evolução, a designação do médico passa para 方士, que significa homem que tem as fórmulas mágicas (tanto medicinais quanto para alquimia) e finalmente para a forma final: o homem que usa álcool e instrumentos cortantes 醫.

Essa evolução marca a transformação não apenas do status social do médico, mas confere a conversão da prática obscurantista em algo baseado não só na experiência do médico, mas também em dados que se acumulam de casos e pacientes atendidos anteriormente, levando a uma espécie primitiva de prontuário. Nasciam, assim, os primórdios da medicina baseada em evidência, com expertise baseada em experiência acumulada em casos clínicos. O conhecimento de fisiopatologia, então precário, dava lugar às especulações filosóficas, de cosmo visão e de crenças e práticas religiosas. Na tentativa de explicar as funções dos órgãos, a fisiopatologia das doenças e posteriormente o porquê das agulhas funcionarem, os antigos médicos (mais filósofos que médicos) chineses recorriam às especulações e às diferentes correntes filosóficas, como as escolas naturalistas (conceito de Yin e Yang, cinco elementos, etc), taoistas (o conceitos de espíritos e alma no corpo) entre outras ${ }^{1}$.

Ao longo da História da Civilização Chinesa, a Medicina Tradicional Chinesa foi lentamente sendo modificada, englobando conhecimento e experiência acumulados por seus praticantes, expandindo e se mesclando principalmente com confucionismo, que entre seus pilares encontra-se a piedade filial, que fortemente recomendava aos seus seguidores cuidarem de seus progenitores na velhice, o que praticamente "obrigava" os seus seguidores a buscar, estudar e praticar a medicina. Ao mesmo tempo, o confucionismo idolatrava o conhecimento geral, recomendava a seus seguidores a acumular conhecimentos literários, científicos, filosóficos, religiosos e de costumes e cultura da sociedade local. Dessa forma, duas consequências imediatamente foram geradas:

1) A Medicina Tradicional Chinesa entrou no rol de "curriculum core" do intelectual da época;

2) A inevitável interação e geração de interfaces entre as diversas áreas de conhecimento dos praticantes do confucionismo.

Como confucionismo pregava a conduta de obediência civil às autoridades e ensinava que a ordem política estabelecida tinha origem divina (pois se os deuses não permitissem, um determinado governo não se estabeleceria), esta corrente ou escola filosófica, que centrava seus ensinamentos em comportamento do indivíduo em relação à família, sociedade e à autoridade, foi rapidamente adotada pelos governos de praticamente todas as dinastias como pensamento oficial do Estado, o que permitiu, indiretamente, a difusão da Medicina Tradicional Chinesa como parte da bagagem cultural necessária de todos os intelectuais. Como os exames de admissão para a administração pública exigiam o conhecimento dos clássicos escritos do confucionismo, a medicina tradicional chinesa fez parte, ainda que de forma indireta, do currículo exigido para ingressar na burocracia oficial (mandarim).

Essa hibridização com o conhecimento dos clássicos do confucionismo acabou por popularizar a medicina tradicional chinesa, e inevitavelmente povoa o cotidiano da população, acessível às pessoas comuns. Por outro lado, a proximidade com a linha filosófica produziu também uma miscigenação entre o conhecimento médico, adquirido na prática médica à beira do leito, com as teorias de orientação filosófica, na tentativa de teorizar a fisiopatologia e mecanismo de ação da fitoterapia e acupuntura. Dessa forma, embora de um lado, muitos médicos da antiguidade começaram a anotar sistematicamente a evolução das doenças, com ou sem intervenção terapêutica do médico, compilando experiências individuais e passando as mesmas de geração em geração, num processo de mestre/aprendiz, gerando evidências, do outro lado, a tentativa de teorizar os fenômenos observados baseando na filosofia e crença, influenciados pelo confucionismo, taoismo e naturismo, e mais tarde pelo budismo, acaba por associar a medicina tradicional chinesa a uma imagem exotérica. Essa imagem só se faria intensificar com a introdução da acupuntura no mundo ocidental, na esteira da "globalização" no final da Dinastia Qing (1644-1912), com as várias potências ocidentais vencendo a China em diversas guerras, obrigando-a a abrir-se para o comércio exterior e a partir desse período, a ter um intercâmbio cultural, e dessa forma, a medicina tradicional chinesa entra no mundo ocidental de forma sistemático. Traduções dos clássicos da medicina tradicional chinesa foram feitas e a mais notável foi a tradução feita por George Soulié de Morant (1878-1955) a partir do clássico Compêndio de Acupuntura e Moxabustão (Zhēnjiǔ Dàchéng 針尒大成) escrito em 1601 por Yang Zizhou $^{2}$. Na tradução, a base filosófica e de crenças religiosas foi destacada, com o emprego de diversos termos 
como energia no lugar de Qi acaba por conferir ainda mais o conteúdo esotérico à prática de medicina tradicional chinesa/ acupuntura. Como uma das modalidades de terapêutica dentro da medicina tradicional chinesa, a acupuntura, assim como as outras modalidades de tratamento, começa a ganhar a individualidade e é vista como uma terapêutica que pode ser aplicada mesmo não observando os princípios distintos de diagnóstico, fisiopatogenia e mecanismos de ação defendidos nos cânones da medicina tradicional chinesa ${ }^{3}$.

Na década de 1960, com a onda da contracultura, a acupuntura é eleita como técnica terapêutica alternativa, o que atrasou o seu reconhecimento como uma prática de saúde baseada em evidência.

Após o reconhecimento da acupuntura a respeito de sua eficácia e evidência pelo National Institutes of Health

\section{REFERÊNCIAS}

1. Needham J. Science and civilization in China, v.6 Biology and biological technology. Part 6: Medicine. Cambridge: Cambridge University Press; 2000.

2. Morant GS. L'acupuncture chinoise. Paris: Maloine; 1939.

3. Lin CA, Hsing WT, Pai, HJ. Acupuntura, prática baseada em evidência. Rev Med (São Paulo). 2008;87(3):162-5. Disponível em: http://www.revistas.usp.br/revistadc/article/ viewFile/59074/62059

4. National Institutes of Health. Consensus Development Statement. Acupuncture. NIH Consensus Statement. 1997 Nov 3-5;15(5). Available from: http://www.healthy.net/scr/ article.aspx? $\mathrm{Id}=2492$

5. Khosrawi S, Moghtaderi A, Haghighat S. Acupuncture in treatment of carpal tunnel syndrome: a randomized controlled em $1997^{4}$, a acupuntura experimenta uma expansão, não apenas na sua prática como em pesquisas. Inúmeros estudos foram realizados recentemente para estudar a sua eficácia, usando ensaios clínicos aleatorizados e controlados ${ }^{5}$, bem como meta-análises ${ }^{6}$.

Apesar de já estabelecida como uma prática reconhecida, inclusive defendida por associações médicas de grande prestígio como Bristish Medical Association ${ }^{7}$, e reconhecida como especialidade médica em diversos países do mundo, inclusive Brasil, a acupuntura ainda continua sendo controversa e objeto de intenso debate ${ }^{8}$. Ainda assim, acupuntura constitui valioso instrumento como arsenal terapêutico validado que pode trazer grande ajuda para não só alívio de sintomas de dor, como em diversas situações clínicas ${ }^{9}$. trial study. J Res Med Sci. 2012;17(1):1-7. Available from: http://www.ncbi.nlm.nih.gov/pmc/articles/PMC3523426/

6. Vickers AJ, etal.Acupuncture for chronic pain. Individual patient data meta-analysis. Arch Intern Med. 2012;172(19):1444-53. doi: 10.1001/archinternmed.2012.3654.

7. SIlvert M. Acupuncture wins BMA approval. BMJ. 2000;321;11. doi:10.1136/bmj.321.7252.11/b.

8. Couqhoun D, Novella SP. Acupuncture is theatrical placebo. Anesth Analg. 2013;116(16):1360-3. doi: 10.1213/ ANE.0b013e31828f2d5e.

9. Manheimer E, Zhang G, Udoff L, Haramati A, Langenberg P, Berman B, et al. Effecs of acupuncture on rates of pregnancy and live birth among women undergoing in vitro fertilization: systematic review and meta-analysis. BMJ. 2008;336:545-9. doi: 10.1136/bmj.39471.430451. 